\title{
Small-aperture corneal inlay in patients with prior radial keratotomy surgeries
}

This article was published in the following Dove Press journal:

Clinical Ophthalmology

25 September 2013

Number of times this article has been viewed

\section{Tukezban Huseynova',* \\ Tomomi Kanamori' \\ George O Waring IV ${ }^{2}$ \\ Minoru Tomita ${ }^{1,3, *}$ \\ 'Shinagawa LASIK Center, Chiyoda-ku, Tokyo, Japan; ${ }^{2}$ Medical University of South Carolina, Storm Eye Institute, Charleston, SC, USA; ${ }^{3}$ Department of Ophthalmology, Wenzhou Medical College, Wenzhou, People's Republic of China}

*These authors contributed equally to this study
Correspondence: Minoru Tomita Shinagawa LASIK Center, Yurakucho ITOCiA I4F, 2-7-I Yurakucho, Chiyoda-ku, Tokyo 100-0006, Japan

Tel $+8 \mid 3522 I 2207$

Fax +8I 352218038

Email tomita@shinagawa-lasik.com
Abstract: This paper describes the 3-month results of two patients who underwent KAMRA $^{\mathrm{TM}}$ (AcuFocus, Inc, Irvine, CA, USA) inlay implantation surgery with a history of prior radial keratotomy. The refractive error just before KAMRA inlay implantation was corrected in one patient with a laser-assisted in situ keratomileusis (LASIK) procedure. The post-inlay implantation surgery results showed effective uncorrected near visual acuity outcomes with no impact on uncorrected distance visual acuity in both patients.

Keywords: KAMRA ${ }^{\mathrm{TM}}$, RK, LASIK, uncorrected distance visual acuity, refractive error, uncorrected near visual acuity

\section{Introduction}

Almost all degrees of myopia, hyperopia, and astigmatism can be corrected to some degree with refractive surgery. Available techniques include laser procedures, implantation of phakic refractive intraocular lenses, and clear lens exchange. ${ }^{1}$ Less frequently used techniques include intracorneal ring implantation and radial keratotomy (RK). The challenge for refractive surgeons is the correction of presbyopia, which affects most people 45 years or older. ${ }^{1}$ According to current estimates, presbyopia is the most common refractive error, affecting more than 2 billion people worldwide. ${ }^{2}$

Barraquer $^{3}$ first described implanting corneal inlays to modify corneal refraction in 1949. Various corneal inlays made of different materials implanted using different surgical techniques, including varying the depth of implantation, have been described over time; however, there are complications, such as corneal stroma opacity, deposits, infiltration, and corneal necrosis due to inadequate nutrition flow between the anterior and posterior layers of the cornea. ${ }^{3}$

The KAMRA ${ }^{\mathrm{TM}}$ corneal inlay (AcuFocus, Inc, Irvine, CA, USA) is made of polyvinylidene fluoride and carbon. Several studies have reported on KAMRA implantation in emmetropic presbyopic ${ }^{4-6}$ and ametropic patients and found the treatment to be safe and effective. ${ }^{7}$ In this report, we describe KAMRA inlay implantation in two patients who had prior RK surgery.

\section{Case I}

A 53-year-old female who had had an RK surgery 15 years prior complained about her near visual acuity. There was no other ocular history of note other than a laserassisted in situ keratomileusis (LASIK) procedure 7 years ago for residual refractive error correction after her RK surgery. On examination, uncorrected and corrected 
visual acuity for near and for distance were checked. The pachymetry before inlay implantation was $498 \mu \mathrm{m}$.

A corneal pocket was created with FEMTO LDV ${ }^{\mathrm{TM}}$ Crystal Line (Ziemer Ophthalmic Systems AG, Port, Switzerland). The pocket formation was done at $270^{\circ}$ inferiorly, not temporally as is usually the case. The surgical technique was targeted to minimize the risk of any intersection with the prior RK incision to avoid the extension of the RK wound into the interface. Using a slit lamp, it was observed that the depth of the inferior incisions was at $40 \%-50 \%$ of the corneal thickness. The other incisions were to a depth of $90 \%$ of the corneal thickness. Considering this, the surgeon preferred to make the pocket at $270^{\circ}$ inferiorly (depth $250 \mu \mathrm{m}$ ). The inlay was removed with forceps from the sterile package and inspected under high magnification for any defects, before being carefully placed in the pocket (Figure 1) over the estimated line of sight based on the midpoint of the first Purkinje image and the pupil center with coaxial patient fixation. ${ }^{7}$

\section{Case 2}

A 46-year-old female with a history of RK surgery 20 years prior was a candidate for presbyopia treatment by KAMRA inlay implantation surgery. Since there was a refractive error as a residual outcome from a prior refractive surgery and the patient complained about her distance vision, a LASIK procedure was performed on the same day as, but just prior to, the inlay implantation surgery. The preoperatively measured pachymetry was $567 \mu \mathrm{m}$.

During the surgery, a $200 \mu \mathrm{m}$ corneal flap was created in the nondominant eye using a femtosecond laser (iFS, Advanced Medical Optics, Inc, Santa Ana, CA, USA). The flap had a superior hinge with a $30^{\circ}$ side cut and a $4 \times 4$ spot-line separation. The refractive error was corrected with an excimer laser (Allegretto Wave ${ }^{\circledR}$ Eye-Q,

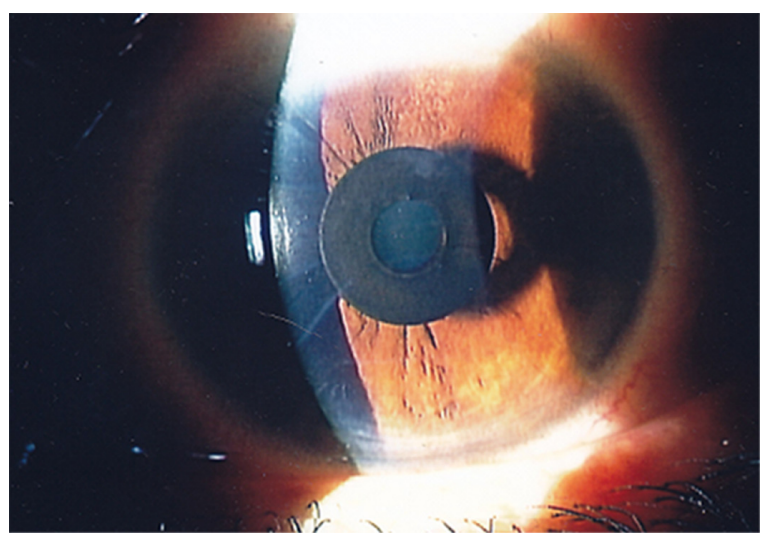

Figure I Post-radial keratotomy surgery eye with implanted KAMRA ${ }^{\mathrm{TM}}$ inlay (AcuFocus, Inc, Irvine, CA, USA), Case I.
Alcon Incorporated, Hünenberg, Switzerland). The target correction was $-0.75 \mathrm{D}$ based on cycloplegic refraction. The LASIK correction and flap replacement were performed in the usual fashion. The inlay was implanted under the flap over the estimated line as described for the patient in Case 1 (Figure 2).

\section{Results}

Preoperative and postoperative results of uncorrected distance visual acuity, corrected distance visual acuity, uncorrected near visual acuity, corrected near visual acuity, and manifest refraction spherical equivalent for both cases are presented in Table 1. For vision evaluation, LogMAR was used, which was converted to Jaeger thereafter for near vision. For distance visual acuity evaluation, the Snellen chart was used. The patient satisfaction questionnaire scores for Case 1 and Case 2 are presented graphically in Figures 3 and 4, respectively. Topography image (Tomey Corporation, Nagoya, Japan) was also estimated in both cases, Figures 5 and 6 .

\section{Follow-up}

The postoperative treatment regimen used with these patients has been described in detail in a previously reported study. ${ }^{7}$ Daily reading was strongly recommended as postoperative training to hasten neuroadaptation. There were no complaints from either of the two patients regarding distance visual acuity and reading performance in any light condition.

\section{Discussion}

The aim of this paper is to report the effectiveness of the KAMRA small-aperture intracorneal inlay in presbyopic patients with a history of a prior refractive surgery. This was one of the exclusion factors in previous reports

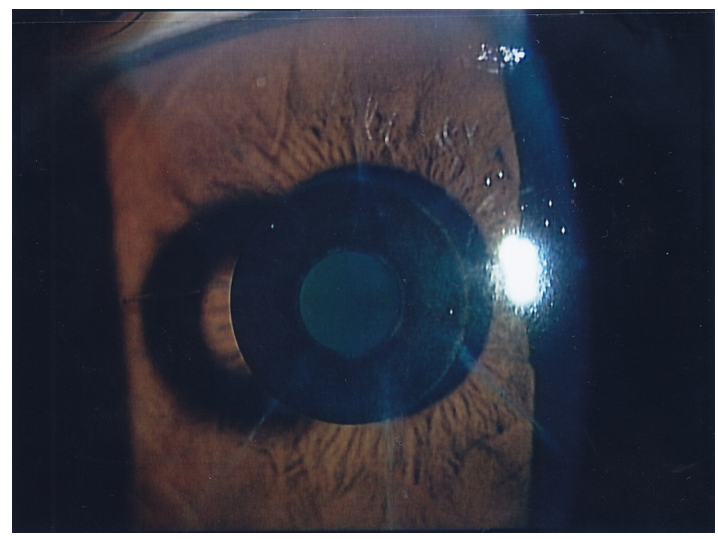

Figure 2 Post-radial keratotomy surgery eye with implanted KAMRA ${ }^{T M}$ inlay (AcuFocus, Inc, Irvine, CA, USA), Case 2. 
Table I Refractive and visual acuity evaluation before and after KAMRA $^{\text {TM }}$ inlay (AcuFocus, Inc, Irvine, CA, USA) implantation

\begin{tabular}{llllll}
\hline Eye & UDVA & CDVA & UNVA & CNVA & MRSE, D \\
\hline Case I & & & & & \\
$\quad$ Preop & $20 / 20$ & $20 / 16$ & $\mathrm{~J} 5$ & $\mathrm{Jl}$ & -0.25 \\
$\quad$ Postop (3 mo) & $20 / 20$ & $20 / 16$ & $\mathrm{Jl}$ & $\mathrm{Jl}$ & -0.75 \\
Case 2 & & & & & \\
$\quad$ Preop & $20 / 200$ & $20 / 16$ & $\mathrm{~J} 2$ & $\mathrm{Jl}$ & -3.5 \\
$\quad$ Postop (3 mo) & $20 / 25$ & $20 / 16$ & $\mathrm{Jl}$ & $\mathrm{Jl}$ & -1.0 \\
\hline
\end{tabular}

Abbreviations: CDVA, corrected distance visual acuity; CNVA, corrected near visual acuity; mo, months; MRSE, manifest refraction spherical equivalent; preop, before operation; postop, after operation; UDVA, uncorrected distance visual acuity; UNVA, uncorrected near visual acuity; D, diopter.

on this inlay. ${ }^{4-7}$ However, because the KAMRA inlay does not have refractive power, it cannot correct refractive errors such as astigmatism, myopia, or hyperopia. ${ }^{7}$ Thus, correction of the residual refractive error in the second case was performed by LASIK procedure.

As is known, RK involves creation of incisions of approximately $90 \%$ depth into the cornea, which flattens it and reduces nearsightedness. One of the primary concerns after RK is refractive instability with a potential hyperopic shift. ${ }^{8}$ The RK incisions were examined in detail under the high magnification of a slit lamp. Neither epithelial cysts nor the presence of any deep vascularization was observed. Ten RK incisions were made in the Case 1 patient, three temporal, three nasal, and two transverse incisions both superiorly and inferiorly. During the RK procedure, the main goal is achieving an incision depth of $80 \%$ to $90 \%$ of the corneal thickness, which is critical in order to obtain a satisfactory surgical result. All incisions in this case were to $90 \%$ of the corneal thickness, except the two inferior incisions, which

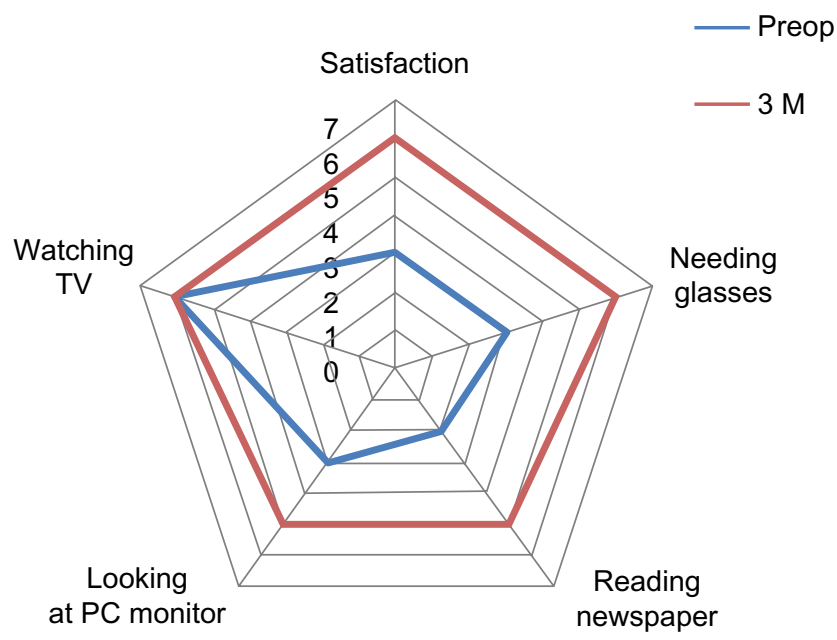

Figure 3 Graph of the patient satisfaction questionnaire results, Case I. Abbreviations: 3 M, 3 months; preop, before operation.

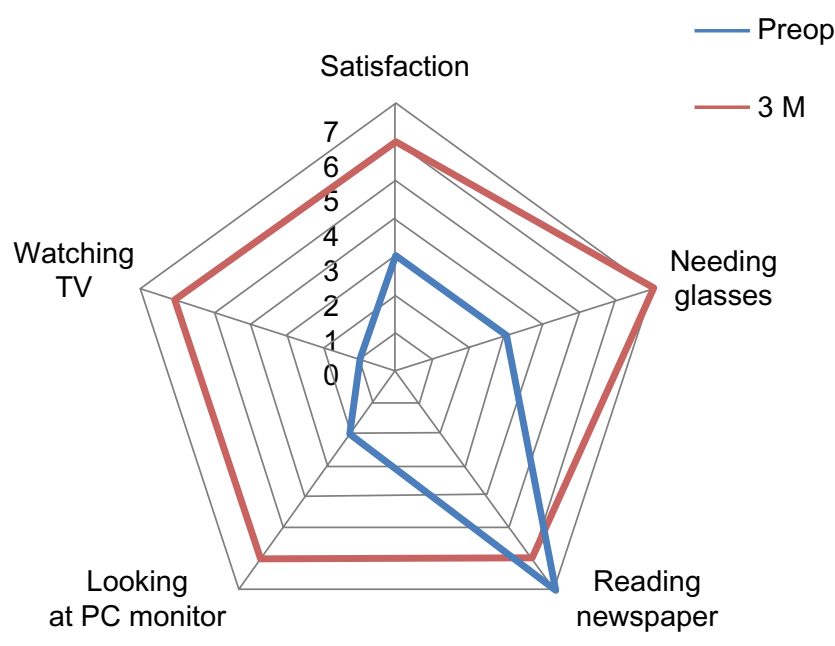

Figure 4 Graph of the patient satisfaction questionnaire results, Case 2. Abbreviations: 3 M, 3 months; preop, before operation.

went to $50 \%$ of the corneal thickness. This was the reason why the surgeon preferred to create the pocket with an inferior $\left(270^{\circ}\right)$ located incision. The pocket depth of $250 \mu \mathrm{m}$ was chosen due to the $140 \mu \mathrm{m}$ corneal flap from prior LASIK surgery. Since the KAMRA inlay should be implanted at the depth of $200 \mu \mathrm{m}$ or deeper, and may not be implanted above a depth of $140 \mu \mathrm{m}$, the corneal pocket was created. Knowing that the safe distance between the previous flap and created pocket should be $100 \mu \mathrm{m}$, the surgeon decided to form the corneal pocket at a depth of $250 \mu \mathrm{m}$, with a safe $110 \mu \mathrm{m}$ of corneal thickness.

There were no complications in terms of the corneal biomechanical structure during the whole follow-up period for both RK patients.

We should also mention night-vision disturbance, dysphotopsia. The term "dysphotopsia" describes a decrease in the quality of vision, different from glare disability, with decreased contrast sensitivity resulting in image degradation. ${ }^{8,9}$ The relationship between dysphotopsia and corneal laser surgery was recognized quite early in the evolution of the process, ${ }^{10}$ when a disparity between the centrally treated corneal zone and the wider pupil, which

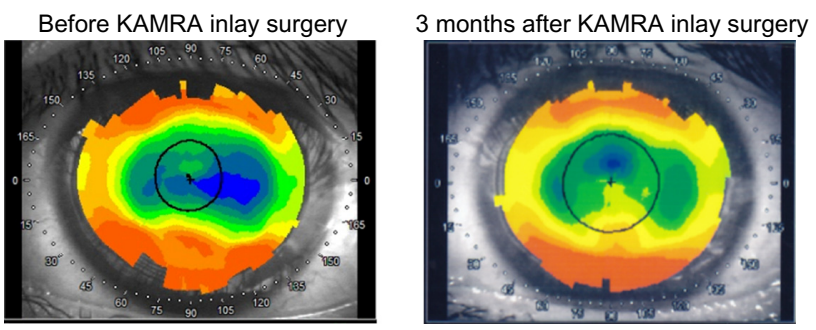

Figure 5 Topography image of Case I patient before (left) and 3 months after (right) KAMRA ${ }^{\text {TM }}$ inlay (AcuFocus, Inc, Irvine, CA, USA) surgery. 


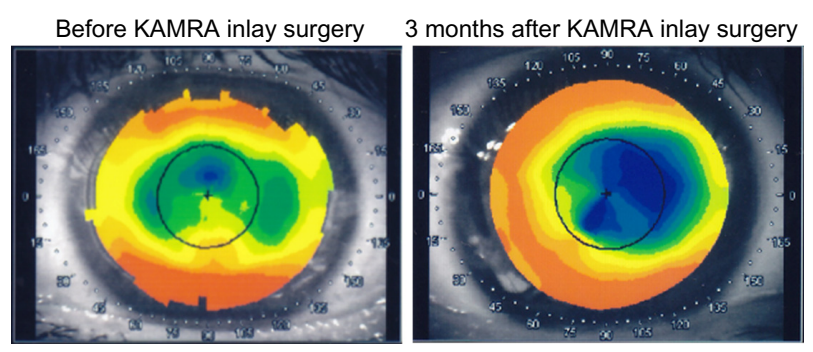

Figure 6 Topography image of Case 2 patient before (left) and 3 months after (right) KAMRA ${ }^{\mathrm{TM}}$ inlay (AcuFocus, Inc, Irvine, CA, USA) surgery.

expands under dim-light conditions, was reported. ${ }^{9}$ Before the era of corneal laser surgery, corneal refractive surgery was conducted with corneal incisions; RK for myopia was the most prevalent type. Difficulty with vision at night such as while driving was the main side effect that patients had to tolerate as a consequence of the radial scars and the small untreated central (optical) zone. ${ }^{11}$ Both patients in our study were questioned about these types of postoperative complication and neither reported any such complications. The uncorrected near visual acuity improved three lines in Case 1, and one line in Case 2, with nine lines gained in uncorrected distance visual acuity due to the simultaneous LASIK procedure at the time of the KAMRA inlay implantation surgery in this patient.

Near visual acuity in Japan is customarily measured at $30 \mathrm{~cm}$ using decimal notation. To our knowledge, there is no internationally accepted standard distance for measuring near visual acuity. In our experience, converting acuity measured at $30 \mathrm{~cm} \operatorname{LogMAR}$ into $40 \mathrm{~cm}$ Jaeger was done as we reported in our previous study. ${ }^{7}$

\section{Conclusion}

The outcomes of the two cases presented suggest that the implantation of the KAMRA inlay may improve the near visual acuity even in patients with a history of prior RK surgery.

\section{Disclosure}

Tukezban Huseynova and Tomomi Kanamori do not have any proprietary interest in any material or method mentioned in this paper. Minoru Tomita and George O Waring IV are consultants for AcuFocus.

\section{References}

1. Baïkoff G, Matach G, Fontaine A, Ferraz C, Spera C. Correction of presbyopia with refractive multifocal phakic intraocular lenses. $J$ Cataract Refract Surg. 2004;30(7):1454-1460.

2. Werner LP, Werner L, Pandey SK, Apple D. Physiology of accommodation and presbyopia. In: Agarwal A, editor. Presbyopia: A Surgical Review. Thorofare, NJ: Slack; 2002:29-60.

3. Barraquer JI. Modification of refraction by means of intracorneal inclusions. Int Ophthalmol Clin. 1966;6(1):53-78.

4. Dexl AK, Seyeddain O, Riha W, et al. Reading performance after implantation of a modified corneal inlay design for the surgical correction of presbyopia: 1-year follow-up. Am J Ophthalmol. 2012;153(5): 994-1001.

5. Jain S, Arora I, Azar DT. Success of monovision in presbyopes: review of the literature and potential applications to refractive surgery. Surv Ophthalmol. 1996;40(6):491-499.

6. Alfonso JF, Fernández-Vega L, Montés-Micó R, Valcárcel B. Femtosecond laser for residual refractive error correction after refractive lens exchange with multifocal intraocular lens implantation. $\mathrm{Am} J$ Ophthalmol. 2008;146(2):244-250.

7. Tomita M, Kanamori T, Waring GO 4th, et al. Simultaneous corneal inlay implantation and laser in situ keratomileusis for presbyopia in patients with hyperopia, myopia, or emmetropia: six-month results. J Cataract Refract Surg. 2012;38(3):495-506.

8. Gayton JL, Van der Karr M, Sanders V. Radial keratotomy enhancements for residual myopia. J Refract Surg. 1997;13(4):374-381.

9. Rosen ES. Night vision disturbance. J Cataract Refract Surg. 2005; 31(2):247-249.

10. O'Brart DP, Lohmann CP, Fitzke FW, et al. Discrimination between the origins and functional implications of haze and halo at night after photorefractive keratectomy. J Refract Corneal Surg. 1994; 10(Suppl 2):S281.

11. Rowsey JJ, Balyeat HD. Radial keratotomy: preliminary report of complications. Ophthalmic Surg. 1982;13(1):27-35.
Clinical Ophthalmology

\section{Publish your work in this journal}

Clinical Ophthalmology is an international, peer-reviewed journal covering all subspecialties within ophthalmology. Key topics include: Optometry; Visual science; Pharmacology and drug therapy in eye diseases; Basic Sciences; Primary and Secondary eye care; Patient Safety and Quality of Care Improvements. This journal is indexed on Submit your manuscript here: http://www.dovepress.com/clinical-ophthalmology-journal

\section{Dovepress}

PubMed Central and CAS, and is the official journal of The Society of Clinical Ophthalmology (SCO). The manuscript management system is completely online and includes a very quick and fair peer-review system, which is all easy to use. Visit http://www.dovepress.com/ testimonials.php to read real quotes from published authors. 